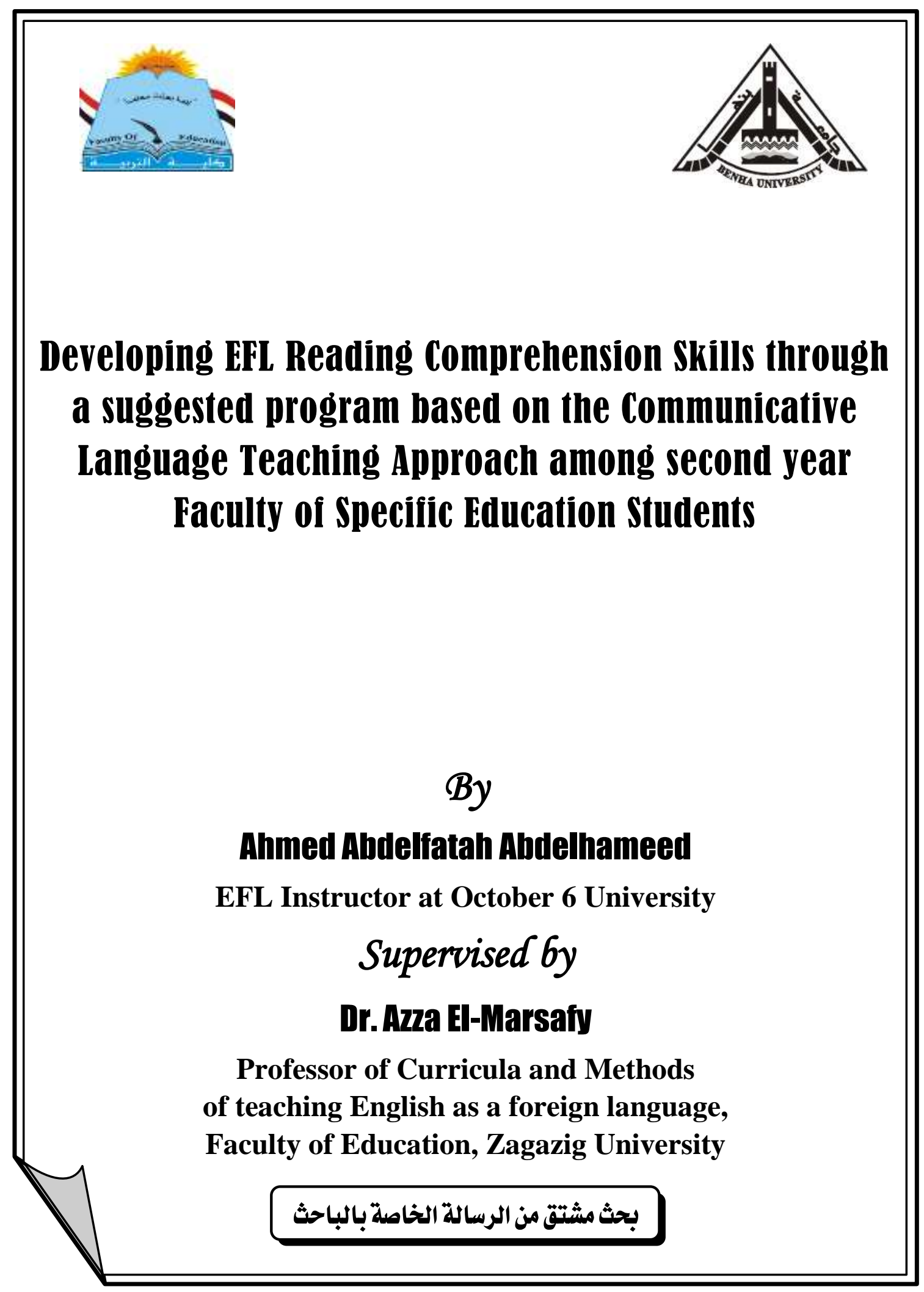




\title{
Developing EFL Reading Comprehension Skills through a suggested program based on the Communicative Language Teaching Approach among second year Faculty of Specific Education Students
}

\author{
By
}

Ahmed Abdelfatah Abdelhameed

EFL Instructor at October 6 University

\section{Supervised by \\ Dr.Azza El-Marsafy}

Professor of Curricula and Methods of teaching English as a foreign language,

Faculty of Education, Zagazig University

\section{Ahstract}

The aim of this study was to develop EFL reading comprehension skills among Faculty of Specific Education students through a suggested program based on the communicative language teaching approach. The quasi-experimental design was used.

The participants were 80students who were randomly divided into two groups: experimental (40) and control (40) from the Faculty of Specific Education, Zagazig University in the first term of the academic year 2019/2020.The instruments of the study were: a) reading comprehension skills checklist , b) reading comprehension test ,c) Rubric for grading the reading comprehension test and the program based on the communicative language teaching approach was taught for two months during the first semester of the academic year 2019/2020 .The experimental group was taught through the program based on the communicative language teaching approach (CLT).On the other hand, the control group was taught using the regular method.

The results indicated that there was a statistically significant difference between the mean scores of both groups in the reading comprehension skills, in favor of the experimental group .It was concluded that the present study proved that the program based on the communicative language teaching approach had a positive effect on developing reading comprehension skills for the second year Faculty of Specific Education students.

Keywords: Reading Comprehension- Communicative Language Teaching Approach. 


\section{Introduction}

Reading is a bridge to world knowledge. Learners obtain knowledge of any field, absorb information of any kind, and explore this changing world through the processing of reading. Reading also helps learners enhance their overall language proficiency, activate their minds, develop their creativity and imagination and widen their vision.

Reading comprehension is the goal and purpose of reading, so there are many researchers who clarified reading comprehension as follows:

To Liu (2010), the reading comprehension skill can be described as a cognitive ability used by the student-readers when interacting with texts .He clarified that reading comprehension involves some sub-skills such as; scanning, skimming, making predictions, guessing the meaning of new words, inferring, understanding text structure, reading for gist, reading for details, making summaries, etc. He showed also that college students need to practice all these reading sub skills to perform English and achieve academic success.

On the other hand, Grabe (2009) asserted that fundamental skills required in efficient reading comprehension are: knowing meaning of words, ability to understand meaning of a word from discourse context, ability to follow organization of a passage and to identify antecedents and references. It is also the ability to draw inferences from a passage about its contents, ability to identify the main thought of a passage, the ability to answer questions answered in a passage, and the ability to recognize the literary devices or propositional structures used in a passage.

According to Amasha (2019), reading comprehension is important to the development of students' learning skills and therefore to their ability to obtain an education. Developing reading skills should be a priority of teaching. According to the researcher's observations, most students do not use reading strategies while reading and processing a text. They also do not have metacognitive awareness in terms of the selectivity and flexibility of using appropriate reading strategies that can 
enhance their comprehension of the text. For example, they do not often set goals of their reading before they start to read. Most students also rarely relate their prior knowledge with the textual content. During reading, they often have problems in decoding and recognizing words. Moreover, they do not monitor their own comprehension and seldom use fix-up strategies when comprehension breaks.

Robinson (2003) has also shown that highly proficient readers utilize a number of different strategies to comprehend various types of texts as follows:

\section{1-Vocabulary:}

The new words are seen by students as a great obstacle to comprehend a text. It is necessary for students to comprehend properly the words or the vocabulary of a written passage in order to be able to decode the message, thus comprehending the written text

\section{2-Working Memory:}

The students often complain of the fact that they can't recall the information they have just read. They need to hold the information in working memory long enough for the information extensively processed, and often some of them lack it.

\section{3-Absence of extensive reading:}

Students read a little or nothing. This is considered a great obstacle for students to comprehend a written text.

\section{4- Type of text:}

The type of text is another factor that has an effect on reading comprehension .It is considered to be one major barrier. Some texts are easy to be perceived and some others are very difficult.

For making sure that the students comprehend the text, Tompkins (2011) pointed out that there are specific characteristics that determine how successfully an individual will comprehend the text including prior 
knowledge about the subject, the ability to infer the new idioms, the main ideas and the supporting details. Thus, the previous skills of reading comprehension are important to help the students overcome the problems that they face in reading the text.

Reading is an important skill that qualifies people to acquire the knowledge and experiences of others. It is a means of language acquisition, communication, and sharing information and ideas. It helps people to develop their characters, activate their minds, enrich their thoughts and widen their vision (Keyser, 2015).

Reading Comprehension is of a vital importance not only in school, but in everyday life. Whether it is the need for learning something new, increasing knowledge, or searching for information, one has to be able to read with comprehension (Maagerø \& Seip Tønnessen, 2006).

Radojevic (2009) stressed the importance of reading comprehension as it relies on two kinds of information: One is received from the text and the other is retrieved from readers' memory .It is an interactive mental process between readers' previous knowledge and knowledge about a given topic. The knowledge of past experiences and prior knowledge in readers' memory are critical in assisting readers to construct meaning from the text. By relating new ideas encountered in the text to familiar ideas and mental constructions, readers can be engaged in reading different materials successfully and learn new information that is required for success in the EFL setting. Besides, according to Kim and Anderson (2011:30), college students who are more proficient readers are most likely to experience more in their courses.

Moreover, Nuefeld (2005:302) emphasized the importance of reading comprehension as teachers fail to develop a good level of understanding the text. He added that reading comprehension involves the integration of different elements of the reading process when reading a text to form a good representation of the text in a student-reader's mind. It is considered as 'the process of constructing a supportable understanding of a text'. 
According to Shanahan (2006:28), reading comprehension is important for successful reading as it includes the construction of meaning more than passive remembering. It is a form of active and dynamic thinking which includes interpreting information through one's own knowledge, inferring what the author doesn't tell explicitly, and many other cognitive processes. Thus, comprehension can be considered the act of understanding and interpreting the information within the text.

The researcher's point of view asserts that reading comprehension is the main gate through which the students can pass and achieve success in all fields of life, not just education.

To shed light on the importance of the reading comprehension skills, the researcher conducted a pilot study on a group of fifteen students selected randomly from the second year Faculty of Specific Education, English section at Zagazig University, where he designed a test related to EFL reading comprehension. The findings showed that there is alack in the following sub-skills of EFL reading comprehension (Determining the main idea, Inferring cause and effect relationships, providing supporting details that develop the main idea, and detecting the new concepts) as shown in table (1).

Table (1) Pilot Study Results of EFL Reading Comprehension Test

\begin{tabular}{||c|c|c||}
\hline $\begin{array}{c}\text { The EFL Reading } \\
\text { Comprehension Skills }\end{array}$ & $\begin{array}{c}\text { The piloted } \\
\text { students' number }\end{array}$ & $\begin{array}{c}\text { Percentage of } \\
\text { Frequency errors(\%) }\end{array}$ \\
\hline \hline a) Determining the main idea & 13 & $87 \%$ \\
\hline $\begin{array}{c}\text { b) Inferring the implied } \\
\text { meaning of the text }\end{array}$ & 12 & $80 \%$ \\
\hline $\begin{array}{c}\text { c) Providing supporting details } \\
\text { that develop the main idea }\end{array}$ & 13 & $87 \%$ \\
\hline d) Detecting the new concepts & 12 & $80 \%$ \\
\hline
\end{tabular}

It was concluded that the EFL students lacked the sub-skills of reading comprehension; therefore the present study was an attempt to develop the level of these students in reading comprehension skills 
through a suggested program based on the communicative language teaching approach. This approach is believed to enhance students' performance and achievement in the sub-skills of reading comprehension and overcoming the difficulties they face.

Communicative language teaching is a recognized theoretical model in English language teaching .It is considered the most effective and widely used approach in EFL/ESL teaching .It has many definitions which differs from one researcher to another as follows:

According to Harmer (2001:85), the communicative approach is closely associated to the notion that "language learning will take care of itself " by plentiful practice. The communicative method emphasizes the interaction in both technique and purpose of learning a language. It is more important to produce language and communicate effectively than to be correct.

$\mathrm{Wu}$ (2007) asserted that CLT is one of the most commonly implemented teaching approaches in L2 classrooms .It puts its primary goal for its learners as the development of abilities and skills to communicate with others and complete the tasks using the L2 in the real world.

At the same time, Brown (2007) referred to the term communicative competence as aspects of the competence that leads to conveying and interpreting messages and to negotiate meanings impersonally within Specific contexts.

Cross (2005) also viewed that communicative language teaching approach is the product of educators and linguists who had grown dissatisfied with the audio-lingual method and grammar-translation methods of EFL instruction.

Larsen-Freeman (2000) argued that CLT refers to a theoretical view of a communicative approach by promoting communication. He also stated that communicative competence is the main objective of teaching any language, by recognizing the interdependence of communication and language. 
The use of communicative language teaching approach creates a good case among the students for communicating each other. They should recognize the activities that help them enhance their communication skills.

According Celce-Murcia (1997), examined the classroom activities used in CLT that help learners develop their communication skills as follows:

\section{1- participation activities:}

In participation activities, students take part in some communicative activities in natural settings .Guided discussions, interviews, and dialogs exemplify these types of activities.

\section{2- Information -gap activities:}

The concept of information gap is an important aspect of communication in a CLT classroom. This is essentially based on the fact that in their daily life people generally communicate in order to get information they don't possess. This is referred to as an information gap. If students can be involved in information gap activities in order to exchange unknown information in language classrooms, authentic communication is likely to occur in the classroom. By doing so, they will draw a available vocabulary, grammar, and communication strategies to complete a task.

\section{3- communication games:}

These games primarily involve information-gap activities which are intended to provoke communication in the classroom. The games are generally in the form of puzzles, drawing pictures and putting things given in the correct order.

\section{4- Role plays:}

In role plays, the students may depend on themselves in their roles. The simplicity of role plays is a matter of student proficiency. The teacher should attach importance to the format of the role play. In the situation, the teacher clearly explains the scene and the plot of the role 
play which is followed by the description of the task and the action to be accomplished. Then, the teacher assigns the roles, the list of characters to make sure that the roles are not too elaborate for the students to carry out. Useful expressions part such as the linguistic information and phrases facilitate the acting out of the roles.

\section{5- Performance activities:}

These are activities in which students prepare something beforehand and deliver their message to the class which can be followed by a classroom discussion. Role plays and dramas are among the examples of performance activities.

\section{6- prepared talks and oral presentation}

These are the talks which are prepared by students about specific topic in the class with the aim of persuading, informing students about a topic or to entertain them.

Thus, the communicative language teaching approach is important for the students as it helps them to communicate with others efficiently and proficiently.

\section{Statement of the problem:}

The problem of the current study is that the majority of EFL students of the second year Faculty of Specific Education are inefficient in the reading comprehension skills lacked EFL; therefore the current study was an attempt to develop the level of these students in EFL reading comprehension skills through a suggested program based on the communicative language teaching approach.

Hence, the following questions were an attempt to tackle such a problem:

What is the effect of a suggested program based on the communicative language teaching approach for developing EFL reading comprehension skills in the light of academic standards among Faculty of Specific Education students? 
The following sub-questions were derived from the above main question:

1- What are the EFL reading comprehension skills required to the Faculty of Specific Education students?

2- How far do the Faculty of Specific Education students have adequate reading comprehension skills?

3- How could the suggested program based on the communicative language teaching approach be designed to develop EFL reading comprehension?

\section{Hypotheses of the study:}

\section{The present study has the following hypotheses:}

1- There is a statistically significant difference between the mean scores of the experimental group participants on the pre-post administrations of the reading comprehension skills test, in favor of the post-administration.

2- There is a statistically significant difference between the mean scores of the experimental and control group participants in the post-administration of the reading comprehension test, in favor of the experimental group.

3- The suggested program based on the communicative language teaching approach has a positive effect on developing EFL reading comprehension skills of the experimental group.

\section{4- Purpose of the study:}

This study aimed at developing EFL reading comprehension skills through designing a suggested program based on the communicative language teaching approach in the light of academic standards among faculty of specific education students. 


\section{5-Delimitations of the Study:}

This study was delimited to:

1- A sample of second year of the Faculty of Specific Education students in the English section, Zagazig University.

2- Ten EFL Reading Comprehension skills appropriate for the second year Faculty of Specific Education students, Zagazig University.

3- The First semester of the $2019 / 2020$ academic year.

\section{6-Significance of the study:}

This study was hopefully expected to be useful to:

\section{1-Faculty of Specific Education students:}

This study was expected to help EFL Faculty of Specific Education students use communicative language teaching approach in developing reading comprehension and writing performance skills.

\section{2-EFL supervisors and teachers:}

This study might provide them with a new instructional model to develop their methods in teaching reading comprehension skills.

\section{3-Curriculum developers:}

Directing the attention of curriculum developers to the importance of communicative language teaching approach to develop teaching reading comprehension.

\section{9-Procedures:}

In order to achieve the aims of the study, the following procedures were adopted:

\section{1-Reviewing relevant literature and previous studies related to:}

A) EFL Reading Comprehension to determine the skills needed for the second year of faculty of Specific Education students, Zagazig University. 
B) The program based on the communicative language teaching approach to design the experiment.

\section{2-Designing the following instruments:}

A) Reading Comprehension skills Checklist.

B) Reading Comprehension skills test.

C) Reading Comprehension skills scoring rubric.

3-Submitting the reading comprehension skills tests to a TEFL jury of specialists to validate their content and modify them to reach their final form.

4- Selecting the study participants of the second year Faculty of Specific Education students and randomly dividing them into two groups: experimental group and control one.

5- Pre-administering the reading comprehension test to both groups of the second year of Faculty of Specific Education students.

6- Designing a program based on the communicative language teaching approach to the experimental group participants.

7- Administering the program based on the communicative language teaching approach only to the experimental group participants.

8- Post-adminstering the reading comprehension tests to both groups after applying the program based on the communicative language teaching approach.

9- Comparing the results of both administrations.

10- Using the appropriate statistical treatment for analyzing the results and discussing them.

11- Drawing conclusion, recommendations and suggestions for further research.

\section{Definition of terms:}

\section{1-Reading comprehension:}

Hans and Hans,(2015, p.63) referred to reading comprehension as "the level of understanding of a text/message. This understanding comes from the interaction between the words that are written and how they trigger knowledge outside the text/message". 
Reading comprehension skill were operationally as a process in which second year of Faculty of Specific Education students have the ability to determine the main ideas, infer the implied meaning of the text, provide the supporting details that support the main ideas and detect the new concepts.

\section{2-Communicative language teaching approach:}

Fariya (2016) refers that communicative language teaching approach is a set of principles about teaching including recommendations about method and syllabus where the focus is on meaningful communication not structure. In this students are given tasks to accomplish using language instead of studying the language.

Communicative language teaching were operationally defined as an approach which aims at developing procedures for the teaching of the four skills (reading, writing, speaking and listening) that acknowledge the interdependence of language and communication. It aims to make students communicatively competent

\section{The Results of the Study}

To prove the homogeneity between the experimental and control groups in the reading comprehension and writing performance before the experimentation, both the writing performance and reading comprehension tests were pre administered to both groups in the first semester of the academic year 2019-2020. They were equivalent before carrying out the experiment. t-test for independent samples was used firstly to find out if there were statistically significant differences between both groups in the pre administration of the reading comprehension test, secondly to find out if there were statistically significant differences between both groups in the pre-administration of writing performance test.(See tables 4 and 5). 
Table (1): Comparing both groups before treatment in the reading comprehension pre-test.

\begin{tabular}{|c|c|c|c|c|c|c|}
\hline Group & $\mathbf{N}$ & Mean & SD & D.F & t-value & Sig \\
\hline \hline control & 40 & 19.6 & 1.62 & \multirow{2}{*}{78} & 0.97 & 0.34 \\
\hline experimental & 40 & 20 & 1.60 & & & \\
\hline
\end{tabular}

As indicated in table (1), there was no a statistically significant difference between both groups on the pre-administration of the reading comprehension test. t-value is $(0.97)$ with significance $(0.34)$.This value is not significant. Thus, both groups were homogeneous in the reading comprehension.

\section{Hypotheses of the study:}

\section{Hypothesis one:}

To test the first hypothesis of the study which states that "There is a statistically significant difference between the mean scores of the experimental group on the pre-post administrations of the reading comprehension skills test, in favor of the post-administration", the researcher analyzed statistically the results of the pre-post administrations of the reading comprehension test for the experimental group participants. The researcher also used a $\mathrm{t}$.test for paired-samples to identify the differences between the mean scores of the experimental group in the pre post administrations of the reading comprehension skills test. (See table 2).

Table (2): Comparing the pre to post administrations results of the experimental group on the reading comprehension test.

\begin{tabular}{||c|c|c|c|c|c|c||}
\hline Administration & $\mathrm{N}$ & Mean & SD & D.F & t-value & Significance \\
\hline \hline pre & 40 & 20 & 1.60 & & & \\
\hline post & 40 & 44.27 & 2.63 & & 44.7 & 0.05 \\
\hline
\end{tabular}


As indicated in table (2), the estimated t-value for reading comprehension test is (44.7) .It is significant at (0.05) level in favor of the post administration of the experimental group participants. This means that the participants reading comprehension were improved. Thus, the first hypothesis has been supported.

\section{Hypothesis two:}

To test the second hypothesis which states that "There is a statistically significant difference between the mean scores of the experimental and control groups in the post-administration of the reading comprehension skills test ,in favor of the experimental group" , the researcher analyzed statistically the results of reading comprehension skills test on the post administration to both groups.

Moreover, the researcher used a $\mathrm{t}$.test for paired-samples to identify the differences between the mean scores of the performance of both groups in the post administration of the reading comprehension skills test. (See table 18).

Table (3): Comparing the reading comprehension post results of both groups.

\begin{tabular}{|c|c|c|c|c|c|c||}
\hline Group & N & Mean & S.D & D.F & t-value & Sig \\
\hline \hline Exp & 40 & 44.27 & 2.63 & & & 5 \\
\hline Cont. & 40 & 18.8 & 1.53 & & 52.85 & 0.05 \\
\hline
\end{tabular}

Table ( 3 ) shows that there is a statistically significant difference at 0.05 level of significance in the reading comprehension test between the mean scores of both groups in the post administration of the reading comprehension test, in favor of the experimental group, $t$-value being 52.85. This value is significant at 0.05 level of significance in favor of post administration of the experimental group. Therefore, this provides enough evidence to support the second hypothesis. 


\section{Recommendations:}

Based on the results of the present study, the following could be recommended:

1- EFL teachers should train students to use a number of reading comprehension strategies and teach them how, why and when to use these strategies independently to read different texts efficiently.

2- EFL teachers should engage students in high-level academic discussions and support students' language acquisition through academic discourse with peers.

3- EFL teachers should encourage students to read different types of texts: magazines, novels and essays and other reading materials that engage them in the reading process.

4- EFL teachers should cooperate with the students inside the class in clarifying the necessary sub-skills of reading comprehension through offering examples of reading texts. 


\section{Appendix [1]}

\section{The Reading Comprehension Skills Checklist}

Name

Date

\section{Dear professor,}

The researcher is conducting a research entitled " Developing EFL Reading Comprehension Skills through a suggested program based on the Communicative Language Teaching Approach in the light of Academic Standards among second year Faculty of Specific Education Students ".

The aim of the research is developing EFL students' reading comprehension skills using a suggested program based on the communicative language teaching approach. Therefore, the researcher prepared the following checklist for identifying EFL reading comprehension skills required for those students.

You are kindly requested to tick ( ) in front of each reading comprehension skill in space provided to determine how far each one is important for the sample concerned. Your suggestions and comments are highly appreciated.

\section{The researcher}

Ahmed Abdelfatah Abdelhameed 
The EFL Reading Comprehension Skills Checklist

\begin{tabular}{|l|l|l|l|l|}
\hline & $\begin{array}{c}\text { EFL Reading Comprehension } \\
\text { Skills }\end{array}$ & $\begin{array}{c}\text { Very } \\
\text { important }\end{array}$ & Important & $\begin{array}{c}\text { Less } \\
\text { important }\end{array}$ \\
\hline \hline 1 & $\begin{array}{l}\text { When reading with comprehension, } \\
\text { EFL Specific Education Students } \\
\text { should be able to: } \\
\text { determine the main idea of the text }\end{array}$ & & \\
\hline 2 & $\begin{array}{l}\text { Summarize the most important } \\
\text { details in the text }\end{array}$ & & \\
\hline 3 & $\begin{array}{l}\text { figure out the purpose of the author } \\
4\end{array}$ & $\begin{array}{l}\text { Determine the detailed ideas of the } \\
\text { text }\end{array}$ & & \\
\hline 5 & $\begin{array}{l}\text { Understand the meaning of } \\
\text { unknown/ difficult words from } \\
\text { context clues }\end{array}$ & & \\
\hline 6 & $\begin{array}{l}\text { Detect the new concepts and } \\
\text { idioms in the text }\end{array}$ & & \\
\hline 7 & $\begin{array}{l}\text { Differentiate facts from opinions } \\
8\end{array}$ & $\begin{array}{l}\text { Connect the text events to prior } \\
\text { experience }\end{array}$ & & \\
\hline 9 & $\begin{array}{l}\text { Distinguish between the words } \\
\text { according to the context }\end{array}$ & & \\
\hline 10 & \begin{tabular}{l} 
Infer cause and effect relationships \\
\hline
\end{tabular} & & \\
\hline
\end{tabular}




\section{Appendix [2]}

\section{The EFL Reading Comprehension Test \\ Dear professor,}

This test is a part of a study entitled "Developing reading comprehension and writing performance skills among faculty of specific education students through a suggested program based on communicative language teaching approach in the light of academic standards".

The study mainly aims at developing EFL reading comprehension skills for the second year Faculty of Specific Education Students through a suggested program based on the communicative language teaching approach .You are kindly requested to respond to the following:

1- The appropriateness of the content to the level of the sample in terms of language length, number of questions and level of comprehension.

2- The suitability of the number of items to cover all the reading comprehension skills in this study.

3- The suitability of items to measure reading comprehension skills.

4- The suitability of test's time limits

If there are any items that need to be added, omitted or modified, please suggest them. 